\title{
LIMITES AO EXERCÍCIO DO DIREITO AO ESQUECIMENTO
}

\section{LIMITS TO THE EXERCISE OF THE RIGHT TO BE FORGOTTEN}

\author{
Viviane Cristina de Souza Limongi \\ Mestranda em Direito Civil na Pontifícia Universidade Católica de São Paulo - PUC/SP. \\ E-mail: vivianelimongi@limongi.adv.br
}

Recebido em: 18/05/2016

Aprovado em: 20/06/2016

Doi: $10.5585 / \mathrm{rdb} . v 14 \mathrm{i} 6.391$

\begin{abstract}
RESUMO: O presente estudo tem por objeto tecer considerações acerca dos limites constitucionais inerentes ao exercício do direito ao esquecimento na sociedade da informação. $\mathrm{O}$ exercício desse direito pressupõe a colisão entre a liberdade de informação e as garantias à privacidade, honra, imagem e sigilo de dados. Os limites ao exercício do direito ao esquecimento estão no interesse histórico, autodeterminação informacional e liberdade de comunicação. $\mathrm{O}$ sopesamento,, pelo Poder Judiciário, desses direitos fundamentais é essencial para a efetividade da proteção do homem, sem que o direito ao esquecimento de informações constitua espécie de censura, mas, tão-somente em defesa das garantias constitucionais.
\end{abstract}

Palavras-chave: Direito ao esquecimento. Direitos fundamentais. Sociedade da informação. Limites; sopesamento.

\begin{abstract}
The object of the presente study is the right to be forgotten and its constitutional limits in the society of information. The exercise of this right indicates the shock between the freedom of information and the rights to privacy, honor, image and data confidentiality. The limits to the exercise of the right to be forgotten are in historical interest, self-determination regarding information and freedom of communication. The balance, by the judiciary, of these fundamental rights is essential for the effectiveness of protection, but it does not seem to be a kind of censorship, but only the defense of constitutional guarantees.
\end{abstract}

Keywords: Right to be forgotten. Fundamental rights. Society of information. Limits. Balance.

SUMÁRIO: Introdução. 1. Direito ao esquecimento: conceito. 2. Limite pelo interesse público. 3. Limite pelo próprio titular: autodeterminação informacional. 4. Limite pela liberdade de informação. Conclusão. Referências.

\section{INTRODUÇÃO}

O presente ensaio tem por objetivo discorrer sobre os limites jurídicos materiais para o exercício do direito ao esquecimento, à luz dos direitos fundamentais, na sociedade da informação.

Falar sobre direito ao esquecimento implica tecer considerações acerca dos direitos fundamentais envolvidos, quais sejam, a liberdade de expressão e a privacidade do indivíduo, ambos expressos, respectivamente, nos incisos IV e X do artigo $5^{\circ}$ da Constituição Federal. 
Ademais, há que considerar o contexto atual da sociedade moderna, denominada sociedade da informação que, com a ferramenta da Internet, se tornou ambiente de difusão de conhecimento e de sociabilização interpessoal, sem filtros, sem limites e em alta velocidade. E mais: com armazenamento dessas informações em caráter perpétuo, pela Internet, eventual dano à imagem, honra e privacidade se mostra perene, pelo que o exercício ao direito ao esquecimento se faz ainda mais necessário.

Assim, para a própria preservação do instituto ao direito ao esquecimento, faz-se necessária a ponderação acerca dos limites jurídicos para seu exercício, pois diante do atual contexto tecnológico, é de suma importância que as garantias fundamentais, principalmente em homenagem à dignidade da pessoa humana, sejam preservadas.

\section{DIREITO AO ESQUECIMENTO: CONCEITO}

\section{O direito ao esquecimento}

é a faculdade que o titular de um dado ou fato pessoal tem para vê-lo apagado, suprimido ou bloqueado, pelo decurso do tempo e por afrontar seus direitos fundamentais. Trata-se de uma espécie de caducidade, onde a informação, pelo decurso do tempo e por sua proximidade com os direitos fundamentais afetos à personalidade, perece ou deveria perecer, ainda que por imposição de lei" (CHEBAB, 2015, p.88)

O direito ao esquecimento guarda, portanto, intrínseca relação com a garantia da privacidade que por sua vez colide com a liberdade de expressão. Ele assume maior relevância na sociedade atual que, com o advento da Internet, apresenta a cada dia um novo paradigma para informação de massa.

Na França, o direito ao esquecimento correlacionou-se, em primeiro lugar, à proteção dos dados pessoais. A Lei n. 78-17, promulgada em $1978^{1}$, tinha por escopo a proteção dos indivíduos contra a utilização abusiva dos seus dados pessoais, nos diversos segmentos da tecnologia. O artigo $1^{\circ}$ da Lei n. $78-17$ afirmava que a tecnologia digital não deveria atentar contra a identidade humana, direitos humanos, vida privada ou liberdade individuais e públicas:

Article 1er. L'informatique doit être au service de chaque citoyen. Son développement doit s'opérer dans le cadre de la coopération internationale. Elle ne doit porter atteinte ni à l'identité humaine, ni aux droits de l'homme, ni à la vie privée, ni aux libertés individuelles ou publiques.

Outros países europeus seguiram a iniciativa da França, conforme demonstram as Diretivas n. 95/46/CE do Parlamento Europeu e do Conselho de 24 de outubro de $1995^{2}$, ambas relativas à proteção dos dados pessoais da pessoa física.

$\mathrm{O}$ conceito atual do que seria o direito ao esquecimento, assim entendido como "esquecer" - e não mais proteger dados pessoais - surgiu em 2011, quando o tema passou a ser debatido pelo Parlamento Europeu ${ }^{3}$.

\footnotetext{
${ }^{1}$ Loi n ${ }^{\circ}$ 78-17 du 6 janvier 1978 relative à l'informatique, aux fichiers et aux libertés, modifiée par la loi no $2004-801$ du 6 août 2004 relative à la protection des personnes physiques à l'égard des traitements de données à caractère personnel.

${ }^{2}$ Directive 95/46/CE du Parlement européen et du Conseil du 24 octobre 1995 relative à la protection des personnes physiques à l'égard du traitement des données à caractère personnel et à la libre circulation de ces données, modifiée par une directive du 12 juillet 2002, elle-même complétée par une directive du 25 novembre 2009.
}

Revista de Direito Brasileira | São Paulo, SP | v. 14 | n. 6 | p. 37 - 50 | maio/ago. 2016 
A dificuldade na criação do conceito jurídico do esquecimento se deu pela vaga interpretação do verbo "esquecer".

Se de um lado, o conceito jurídico apresentava conotação negativa, na medida em que seria um obstáculo à conservação de conhecimento, permitindo a reprodução de erros cometidos no passado - "l'oubli evoque l'échec, la défaillance de la mémoire et rêvet alors une coloration negative"(BOIZARD, 2015, p. 8) - de outro lado, o conceito trazia uma conotação positiva, consubstanciada pela faculdade de não lembrar; de o indivíduo estar e permanecer só: "(...) l'oubli c'est la volonté, la faculté d'oublier. (...) C'est la capacité à oublier que développe l'individu parce que cela lui est nécessaire. Dans cette dimension, l'oubli comporte une fonction constructive, voire réparatrice" (BOIZARD, 2015, p. 8).

Sobre o conceito positivo do direito ao esquecimento, Nietzsche defende que o esquecimento é uma faculdade essencial ao desenvolvimento do ser humano, em prol da ordem psíquica e serenidade, "nul bonheur, nulle sérénité, nulle esperance, nulle dierté, nulle jouissance de l'instant présent ne pourrait exister sans faculté d'oubli" (NIETZSCHE, 1874 apud BOIZARD, 2015, p. 8)

Segundo IZQUIERDO, Iván (2010, apud MOUTINHO, 2015, p. 304), “O esquecimento é uma necessidade tão vital para o ser humano quanto a lembrança, permitindo selecionar as informações recebidas constantemente, preservando as que são significativas e descartando as demais".

Mas foi com o advento da sociedade da informação, alterando a dinâmica do esquecimento - pois, ao contrário do ser humano, a rede de computadores possui memória digital perfeita e ilimitada - que a angústia pela preservação dos direitos fundamentais se tornou evidente.

En permettant l'avènement d'une mémoire numérique parfaite, (cette révolution numérique) a opéré um reversement de l'équilibre mémoire/oubli' (QUILLET, 2011 apud BOIZARD, 2015, p. 9). Elle a 'fondamentalement bouleversé le type d'information dont il est posisible de se souvenir, la manière dont on s'em souvient, et à quel coût (...). De manière evidente, le souvenir est devenu la norme, et l'oubli l'exception' (SCHÖNBERGER 2009 apud BOIZARD, 2015).

O fenômeno da Internet trouxe à balha novas tecnologias e dimensões de difusão de conhecimento, sociabilização interpessoal e coleta de informações, de modo que a definição de privacidade - como o direito de estar só (to let be alone) - teve sua abrangência diminuída (RODOTÀ, 2008, p. 24).

As novas tecnologias na informação - a despeito de promoverem a globalização e melhoria na troca de informações - também têm gerado angústia à sociedade, pois desnudam a forte defasagem entre a rapidez do progresso científico e a obsolescência das soluções jurídicas (RODOTÀ, 2008, p. 42).

E pela angústia na preservação dos direitos fundamentais, e, principalmente, no tocante à privacidade, é que o direito ao esquecimento adquiriu maior relevância e veio sendo reconhecido pela jurisprudência internacional, mesmo antes de ter seu conceito jurídico definido.

\footnotetext{
${ }^{3}$ Proposition de règlement du Parlement européen et du Conseil relatif à la protection des personnes physiques à l'égard du traitement des données à caractère personnel et à la libre circulation de ces données, plus simplement nommé Règlement general sur la protection des données, COM/2012/011 final - 2012/0011 (COD).

Résolution législative du Parlement européen du 12 mars 2014 sur la proposition de règlement du Parlement européen et du Conseil relatif à la protection des personnes physiques à l'égard du traitement des données à caractère personnel et à la libre circulation de ces données (règlement général sur la protection des données) (COM(2012)0011 - C7-0025/2012-2012/0011(COD)).
}

Revista de Direito Brasileira | São Paulo, SP | v. 14 | n. 6 | p. 37 - 50 | maio/ago. 2016 
$\mathrm{O}$ direito ao esquecimento surge pela necessidade de garantir à pessoa humana a tutela do direito geral de personalidade, dentre os quais CANARIS (1994 apud MOTA, 2000, p. 75) especifica o direito à autodeterminação informacional, consubstanciada pela tutela de proteção perante a divulgação de afirmações pessoais e fatos verdadeiros.

Trata-se do esquecimento, pela sociedade, de situações que causam desconforto, tristeza, sofrimento e dor, sempre com fundamento no princípio da dignidade humana e inviolabilidade pessoal (arts. $1^{\circ}$, III, E 5 ${ }^{\circ}, \mathrm{X}$, da CF/1988). (CHEHAB, 2015)

Para RULLI (2012), o direito ao esquecimento é direito fundamental associado à dignidade humana e à inviolabilidade pessoal, nos termos dos $\operatorname{artigos} 1^{\circ}$, III; e $5^{\circ}, \mathrm{X}$, da Constituição Federal de 1988.

Segundo CHEHAB (2015, p. 90), "negar a existência do direito ao esquecimento é admitir pena de caráter perpétuo". Ainda segundo o Autor, "o direito ao esquecimento guarda relação direta com a privacidade que permite ao cidadão o direito de se manter na solidão, no anonimato, na reserva ou na intimidade".

Mas, em uma sociedade da informação, como garantir a efetividade do direito ao esquecimento em razão das informações publicadas na Internet? Como resolver a colisão entre direitos fundamentais, mais especificamente entre os princípios da liberdade de expressão e o da privacidade? Ou a privacidade tornou-se mera utopia constitucional?

Denota-se, pela definição proposta por CANARIS (1994 apud PINTO, 2000), que o direito ao esquecimento poderia estar incluído no domínio de proteção relacionado à autodeterminação informacional do indivíduo, ou seja, a tutela do indivíduo em decidir quais afirmações pessoais e fatos verdadeiros seriam disponibilizados no espaço público e quais não seriam.

Surge, portanto, a necessidade de precisar o núcleo em que repousa a ideia da vida privada e a distinção desta, em relação à vida pública, conforme ensinamentos de SERPA (SERPA, 1994, p. 162).

Assim, para garantir o direito à autodeterminação informacional, nasce o direito ao esquecimento pela "proteção perante lesões da liberdade de decisão", conforme ensinamentos de CANARIS, esposados por PINTO (2000, p. 75).

Decorre do direito geral de personalidade, defendido na jurisprudência alemã, que passou a tratá-lo como direito fundamental para "garantir da esfera de vida mais restrita e a conservação de suas condições de base, no sentido do princípio constitucional superior da dignidade da pessoa humana", conforme esposado no BVerfGE, vol. 24. p. 148 e ss. ("Epler"), esp. 153.

Contudo, o direito à autodeterminação informacional e, contrario sensu, o direito ao esquecimento, ainda que constituam facetas do direito geral de personalidade, devem ser ponderados no caso concreto e, se necessário, devem sofrer limitações. Esse é o entendimento de SCHREIBER, Anderson (2013, p. 13):

a privacidade se sujeita, como qualquer outro direito da personalidade, a ponderações que, à luz das circunstâncias concretas, a fazem ora prevalecer, ora ceder passagem a outros interesses que, também voltados à realização e desenvolvimento da pessoa humana, mostram-se merecedores de igual proteção pela ordem jurídica.

Se os direitos da personalidade se sujeitam ao crivo da ponderação, o direito ao esquecimento não fica atrás. Segundo CHEHAB (2015), o direito ao esquecimento deve ser ponderado à luz da História, atividade pública, interesse jornalístico. Enfim, de forma geral, o direito ao esquecimento - como decorrência da privacidade - cede espaço à relevância 
informativa ou histórica, ou, ainda, se o próprio indivíduo, em momento anterior, renunciou à parte de sua esfera privada.

Patente está a estreitíssima ligação entre o direito ao esquecimento e a privacidade. Trata-se de decorrência lógica pautada, em sua essência, "nas razões de tranquilidade e solidão do indivíduo, partes integrantes da vida privada em círculo menor, ou mais interior", conforme ensinamentos de juristas como Lucien Martin e William Swandler que enfatizam o direito de se viver isoladamente, "sem estar submetido a uma publicidade que não provocou nem almejou" (SERPA, 1994, p. 172).

Mas como o conceito de privacidade não é absoluto, nas palavras de SCHREIBER (2013), há de observar as manifestas limitações que justifiquem a quebra da muralha entre o campo privado e público.

SERPA (1994, p. 175) salienta a existência de três "justas causas" - termo cunhado por BRICOLA em sua obra Prospective e Limite Della Tutela Penale Della Tutela Penale Della Rizervatezza - para limitação do direito à privacidade: a) causa de interesse público; b) causas de interesse pessoal do próprio titular na privacidade ao determiná-las em certas e específicas condições, como por exemplo, uma prova de inocência; e, c) causas referentes ao direito à informação entre particulares ou com relação às entidades públicas ou privadas.

No tocante às exceções ao exercício do direito ao esquecimento, CHEHAB (2015, p. 97) especifica o "interesse público" supramencionado para inserir (a) os fatos relacionados à História; (b) fatos vinculados ao exercício de uma atividade pública de uma figura pública. No tocante à limitação referente às "causas de interesse pessoal", CHEHAB (2015) insere o (c) interesse da pessoa condenada em demonstrar sua inocência ou grave injustiça; e (d) a busca da verdade sobre si, como por exemplo, o direito de conhecer sua própria identidade genética.

\section{LIMITE PELO INTERESSE PÚBLICO}

No tocante às causas de interesse público, esmiuçadas por CHEHAB (2015) para constar também os fatos relacionados à História ou vinculados ao exercício de uma atividade pública de uma figura pública, trata-se de interferência prevista em lei e que

constitua medida que, numa sociedade democrática, seja necessária para segurança nacional, a segurança pública, o bem-estar econômico do país, a defesa da ordem e a prevenção das infrações penais, a proteção da saúde, ou da moral, ou a proteção dos direitos e liberdade dos demais. (SERPA, p. 175)

Citando Miguel Urabayen, SERPA (1994, p. 176) ensina que as causas justas de interesse público se justificam pela segurança pública, interesse estatal na investigação criminal, registro histórico, causa cultural, assim entendida como o registro bibliográfico de notoriedades (artistas, políticos, estadistas, sacerdotes religiosos etc.). (p. 176)

A limitação histórica, segundo CHEHAB (2015, p. 96) se justifica pelo interesse da sociedade em conhecer os erros do passado, superando-os para não os repetir: "é a lupa que nos faz descobrir quem somos, de onde viemos e para onde vamos. É o elo indissolúvel que ligada passado, presente e futuro".

Nas palavras de FACHIN, Zulmar Antônio, "A História precisa ser o espelho fiel do tempo. Em nome desta verdade, os fatos e a imagem de certas pessoas podem e precisam ser divulgados, independentemente ou não de autorização". (1999, p. 112)

Contudo, na sociedade da informação que vive e sobrevive de informações, mister se faz diferenciar conteúdo histórico, com real relevância para a sociedade, de conteúdo mesquinho, especulativo, para ganhar audiência e para fins patrimoniais. 
SERPA afirma que se impõe distinguir o "lídimo interesse público, do interesse do público, sedento de curiosidade, de mórbida indiscrição e maledicência” (1994, p. 186).

NOVOLENE (apud SERPA, p. 186) propõe, nesse intuito, a expressão "Interesse social de relevância”.

Por esse motivo, no que concerne à limitação histórica, faz-se necessária a ponderação dos princípios, no caso concreto, quando se poderá extrair a melhor solução jurídica para solução do caso.

O direito ao esquecimento, cuja análise está, atualmente, sob o crivo do Supremo Tribunal Federal, talvez tenha tido seu caso mais emblemático na Alemanha, no caso Lebach I (BVerfGE 35,202), quando o Tribunal Constitucional Alemão, em 1969, concedeu medida assecuratória para impedir a exibição de um programa televisivo pouco antes de um dos condenados deixar a prisão, após cumprimento de pena de seis anos de reclusão.

O Tribunal Estadual, inicialmente, rejeitou medida cautelar para obstar a exibição, medida essa confirmada pelo Tribunal Superior Estadual, o que ensejou, por parte do autor reclamação constitucional.

ALEXY (2006, p. 100), ao discorrer sobre a argumentação do Tribunal Constitucional Federal alemão, no caso Lebach, salientou a "situação de tensão entre a proteção da personalidade, garantida pelo art. $2^{\circ}, \S 1^{\circ}$, combinado com o art. $1^{\circ}, \S 1^{\circ}$, da Constituição alemã, e a liberdade de informar por meio de radiodifusão, nos termos do art. $5^{\circ}, \S 1^{\circ}, 2^{\prime}$.

Em seguida, após a constatação da colisão entre princípios cujos valores abstratos estão no mesmo nível, o Tribunal Constitucional Federal, nas palavras de ALEXY (2006, p. 101), sustentou uma "precedência geral da liberdade de informar (P2) no caso de uma informação atual sobre atos criminosos". Ou seja, havia uma condição de precedência, tendo por finalidade o interesse social, que gerou uma "preferência" na escolha do valor colidido.

$\mathrm{Na}$ terceira etapa do julgamento, o Tribunal Constitucional Federal entendeu que

a repetição do noticiário televisivo sobre um grave crime, não mais revestido de um interesse atual pela informação, que coloca em risco a ressocialização do autor, a proteção da personalidade (P1) tem precedência sobre a liberdade de informar (P2), o que, no caso em questão, significa a proibição da veiculação da notícia”. (ALEXY, 2006, p. 101)

Segundo ALEXY (2006), o conflito desses valores constitucionais não poderia ser solucionado pela singela declaração de invalidade de uma das normas, mas por meio de um real sopesamento entre os valores constitucionais, optando-se pela cessão de um dos interesses em prol do outro, de acordo com as circunstâncias do caso concreto.

O sopesamento entre as normas fundamentais é desafio a ser enfrentado pelos Tribunais Constitucionais e pela sociedade que ponderará se aquela situação é fundamental à manutenção de sua própria História ou se cederá espaço ao direito individual no exercício do direito geral e fundamental de personalidade.

Nosso entendimento é que a História seja preservada, mas que ao indivíduo - a despeito das dificuldades técnicas encontradas na Internet para efetivação do esquecimento da informação - seja facultado o real exercício do direito geral de personalidade.

Afinal, assim já caminham os precedentes do Supremo Tribunal Federal que, na seara criminal, reconhece repercussão geral no direito ao esquecimento, a despeito de, no Superior Tribunal de Justiça, prevalecer tese contrária:

MATÉRIA PENAL. FIXAÇÃO DA PENA-BASE. CIRCUNSTÂNCIAS JUDIDICAIS. MAUS ANTECEDENTES. SENTENÇA CONDENATÓRIA EXTINTA HÁ MAIS DE CINCO ANOS. PRINCÍPIO DA PRESUNÇÃO DE 
NÃO-CULPABILIDADE. MANIFESTAÇÃO PELO RECONHECIMENTO DO REQUISITO DE REPERCUSSÃO GERAL PARA APRECIAÇÃO DO RECURSO EXTRAORDINÁRIO. (RE 593818 RG, Relator(a): Min. JOAQUIM BARBOSA, julgado em 26/02/2009, DJe-064).

\section{LIMITE PELO PRÓPRIO TITULAR: AUTODETERMINAÇÃO INFORMACIONAL}

No tocante à limitação imposta pelo próprio titular, divisa-se a situação de outorga pelo próprio concedente para redução do direito à privacidade, observando-se a impossibilidade de serem ultrapassados os limites da própria permissão. (SERPA, 1994, p. 176).

Trata-se da limitação do direito ao esquecimento pela renúncia tácita do indivíduo à autodeterminação individual, no campo do direito privado, em que também se requer a análise da colisão do direito à privacidade do indivíduo e o armazenamento de informações por ele mesmo disponibilizadas anteriormente, conforme ensinamentos de CACHAPUZ (2014, p. 352).

Segundo CACHAPUZ (2014, p. 342-353), encampando posição de Hannah Arendt, a questão de fundo é o "impulso à autoexposição", quando o indivíduo deseja aparecer, e em determinada medida, fazer-se visto "por feitos e palavras" e posterior arrependimento pelo excesso de exposição.

Assim, não há como desconsiderar a utilização, pelo indivíduo, de um espaço considerado público e comum para se expor, promover-se, fazer-se visto por feitos e palavras, conforme ensinamentos de ARENDT (apud CACHAPUZ, 2014).

Se o próprio indivíduo se utiliza do espaço público para promover-se, renunciando às esferas mais privadas, aplica-se, também nesse caso, o direito ao esquecimento? Ou o indivíduo se equipara aos políticos e pessoas públicas? Qual a diferença das esferas de privatismo? Aplicase, diretamente, a tutela geral ao direito da personalidade, conforme proposição de CANARIS (PINTO, 2000)?

Para melhor pontuar a diferenciação entre essas camadas entre maior e menor privatismo e, consequentemente, maior ou menor tutela aos domínios propostos por CANARIS, sugere-se a utilização da teoria das esferas.

Segundo CORDEIRO (2007, p. 240), a teoria das esferas desenvolvida pela doutrina tem por objetivo tentar definir o nível de reserva ao direito da personalidade envolvido. Nesse contexto, haveria, sucessivamente, as seguintes esferas:

Uma esfera pública: própria de políticos, actores, desportistas ou outras celebridades, ela implicaria uma área de condutas propositadamente acessível ao público, independentemente de concretas autorizações;

Uma esfera individual-social: reporta-se ao relacionamento social normal que as diversas pessoas estabelecem com amigos, colegas e conhecidos; (...)

Uma esfera privada: tem a ver com a vida privada comum da pessoa: apenas acessível ao círculo da família ou dos amigos mais estreitos, equiparáveis a familiares;

Uma esfera secreta: abrange o âmbito que o próprio tenha decidido não revelar a ninguém; desde o momento em que ele observa a discrição compatível com tal decisão, esta esfera tem absoluta tutela.

CACHAPUZ (2006, p. 118) encampa ensinamentos de CORDEIRO (2007) e divide as esferas de privacidade em três níveis: a mais íntima, dotada de maior privatismo e proteção jurídica da pessoa, situações protegidas pelo chamado "Direito Privado clássico"; a segunda camada, onde estão as necessidades concernentes a moradia, alimentação e vestuário, incluindo relações de consumo. A terceira, no tráfico econômico em sentido estrito, chamado tráfico social 
em que há o híbrido entre o público e o privado. Em termos do direito do esquecimento, é essa esfera que interessa ao presente estudo.

É certo que exista o direito de "permanecer só", consigo mesmo, sem interferência de terceiros, como dito acima. E seguindo-se o princípio do "to let be alone", CACHAPUZ (2006, p. 127) afirma que cada um tem o direito, em princípio, de determinar se, e em que medida, terceiros poderão levar ao âmbito público relatos de sua vida ou de certos eventos desta.

Segundo BIANCA, C. Massimo (2005, p. 37), trata-se da tutela della riservatezza, conforme ensinamentos de Adriano de Cupis em meados do século XX. (p. 37 texto)

Segundo CORDEIRO (2007), BIANCA (2005) e CACHAPUZ (2006), não se nega a existência da esfera íntima e privada a todos os indivíduos. Não se nega o direito de estar só, de ser esquecido

O dilema, contudo, traduz-se pela renúncia dessa esfera íntima para promover-se.

Ao citar ensinamento clássico de Robert Alexy (CACHAPUZ, 2006, p. 119), pelo qual "há que se tratar o igual igualmente e desigualmente o desigual) consubstanciado no princípio da igualdade fática, CACHAPUZ (2006, p. 120) afirma não há como se admitir que a mesma solução atinja, abstratamente, a esfera pública reservada ao político e de um homem comum, sob pena de admitir-se a própria negação à atuação de um princípio de igualdade jurídica.

Divisa-se, portanto, certa limitação ao exercício pleno do direito da personalidade do indivíduo que é público, exerce atividades relacionadas ao interesse público ou utiliza o espaço público para promover-se (artistas, celebridades, esportistas, políticos etc.) do indivíduo comum.

Por óbvio que ao político - como a qualquer indivíduo - é reservada a manutenção de sua esfera secreta. No entanto, aplicar a ele, político, o mesmo direito ao esquecimento do que a um homem comum, seria violar o próprio princípio da igualdade substancial, proposto por ALEXY (2006).

Essa limitação ao direito subjetivo ao esquecimento se refere, portanto, às atividades públicas de figuras públicas - conforme exposto por CHEHAB (2015) - bem como à renúncia ao direito de autodeterminação informacional do indivíduo, que se utiliza do espaço público para promover-se.

Reitere-se: não significa que não exista proteção jurídica em caso de violação dos limites, mas apenas certa mitigação do direito ao esquecimento.

A despeito dessas duas limitações - histórica e pela autodeterminação individual - há a limitação referente ao espaço destinado à crítica, livre manifestação e liberdade dos meios de comunicação, previstas no artigo $5^{\circ}$, inciso IV; e 220, parágrafos $1^{\circ}, 2^{\circ}$ e $6^{\circ}$, todos da Constituição Federal.

\section{LIMITE PELA LIBERDADE DE INFORMAÇÃO}

A terceira limitação se refere, de modo abrangente, ao direito de informação e liberdade dos meios de comunicação.

Sobre liberdade de expressão, o Ministro Marco Aurélio Mello (2009, p. 239) já teve a oportunidade de destacar:

Há de se proclamar a autonomia do pensamento individual como uma forma de proteção à tirania imposta pela necessidade de adotar-se sempre o pensamento politicamente correto.

O Ministro cita Stuart Mill e afirma que não existe uma verdade absoluta que justifique limitações à liberdade de expressão individual.

BASTOS, Celso Ribeiro (1997) entende que:

Revista de Direito Brasileira | São Paulo, SP | v. 14 | n. 6 | p. 37 - 50 | maio/ago. 2016 
O homem não se contenta com o mero fato de poder ter as opiniões que quiser, vale dizer, ele necessita, antes de mais nada, saber que não será apenado em função de suas crenças e opiniões. É da sua natureza, no entanto, ir mais longe: o procurar convencer os outros; o fazer proselitismo.

Divisa-se, nesse aspecto, que a liberdade de expressão também constitui uma das facetas do direito da personalidade, pois é a partir da troca de informações e opiniões que o homem desenvolve, com a liberdade, sua personalidade.

O direito ao esquecimento não pode coarctar a garantia subjetiva e individual de tecer críticas, opiniões, crenças que, conforme ensinamentos acima, estão longe de constituir violações a direitos da personalidade, mas, sim, o exercício da garantia constitucional de emitir opiniões.

Por outro lado, na sociedade da informação, sedente de curiosidade e maledicência, fazse necessária a ponderação da liberdade de crítica com o direito ao esquecimento ou de retificação. JUNIOR, Otavio Luiz Rodrigues (2013), em seu artigo denominado "Não há tendências na proteção do direito ao esquecimento", afirma que a União Europeia, por meio da Diretiva de Proteção de Dados, em sua nova redação do artigo 16, especificou o conceito do direito a pagar ("right to erasure") ou retificar dados ("right to rectification"), justamente em prol do direito geral de personalidade.

O espaço da crítica e livre opinião deve ser preservado, pois talvez seja uma das maiores conquistas constitucionais da sociedade brasileira após o fim do regime militar, mas mister se faz a observância das eventuais violações que poderão ser objeto do exercício do direito ao esquecimento ou do direito de resposta, faceta do direito ao esquecimento, consubstanciada pela possibilidade outorgada à pessoa mencionada em um jornal ou escrito periódico, de fazer inserir uma resposta ao artigo, naquela mesma publicação ou onde fora mencionada.

Há ainda de observar-se a limitação do direito ao esquecimento pelo direito à informação, comunicação social, liberdade de imprensa.

Segundo SERPA (1994, p. 177), o direito à informação, seja de fonte pública ou privada, pode ser encarado sob dois aspectos: o direito de ser informado e o direito de coletar informações necessárias para serem utilizadas pela fonte coletora.

Ambos os aspectos derivam do dever de informar, fundamental no sistema liberal das democracias e pilar do estado democrático de direito.

Sobre o direito fundamental de informação, trazemos à colação as palavras de ZULIANI, Enio (2007, p. 43),

(...) a imprensa é titular de um direito fundamental, qual seja o de livre expressão de pensamento e de comunicação, de modo que é preciso refletir, quando se analisa a oportunidade de uma liminar de abstenção de atividade da imprensa, a extensão do dano coletivo com a obstrução da notícia. (...)

Não existe uma fórmula mágica para bem solucionar esses conflitos da imprensa versus direito individual e nem poderia haver a pretensão de criar, com esses breves comentários, um mecanismo salvador dessas dificuldades judiciárias. $\mathrm{O}$ que importa é que o processo civil está reformulado e pronto para tutelar, quando necessário, a honra que se quer enxovalhar de forma astuciosa, arbitrária e leviana.

Por outro lado, o que se tem de permitir à imprensa é o uso, e não o abuso da liberdade de opinião, informação e expressão, nas palavras de HUNGRIA, Nelson (1958, p. 292).

Nas palavras de FERNANDES (1997, p. 203), o exercício da imprensa deve pautar-se pela responsabilidade da informação divulgada, sob pena de violação aos direitos fundamentais do indivíduo:

Revista de Direito Brasileira | São Paulo, SP | v. 14 | n. 6 | p. 37 - 50 | maio/ago. 2016 
uma indiscrição, cujo contemplamento a lei não pode sufragar. Antes, haverá de coibi-la, protegendo a vida privada. Já em consequência uma compatibilização a ser feita do progresso da técnica com o direito à vida privada; entre o dever da imprensa de noticiar e o direito do indivíduo de viver em paz, sendo bem informado.

Ao discorrer sobre a prevalência do direito à informação, ZULIANI (2007, p. 43) afirma que o Judiciário, na disputa pela predominância do direito de livre expressão do pensamento e da comunicação com o direito à inviolabilidade de atributos da vida privada, não pode ignorar a voz uníssona da doutrina no sentido da primazia do direito de informar e de ser informado (art. 220 da CF).

Nesse sentido, aliás, prevaleceu o entendimento do Plenário do Supremo Tribunal Federal que julgou procedente a Ação Direta de Inconstitucionalidade (ADI) n. 4815 para declarar inexigível autorização prévia do biografado para publicação de biografias ${ }^{4}$.

Ainda, na ocasião do julgamento da ADPF n. 130, o Pretório Excelso decidiu pela não recepção, pela Constituição de 1988, da Lei 5.250/67 (Lei de Imprensa), vigente no período da ditadura militar. À época, o Ministro Celso de Mello (2009), manifestou sua posição pela revogação total da Lei de Imprensa. Segundo ele, "nada mais nocivo e perigoso do que a pretensão do Estado de regular a liberdade de expressão e pensamento".

Sobre as críticas, o Ministro mencionou que, "quando emitidas com base no interesse público, não se traduzem em abuso de liberdade de expressão, e dessa forma não devem ser suscetíveis de punição" (2009).

Por outro lado, frisou que a mesma Constituição garante também outros direitos fundamentais, como os direitos à inviolabilidade, privacidade, honra e à dignidade humana, pelo que seriam esses os valores que limitariam a liberdade de imprensa e que ao Poder Judiciário caberia definir, no caso concreto, com base no princípio da proporcionalidade, qual direito prevalecer.

Assim, a solução para o conflito entre os direitos da personalidade, aqui apresentado como o direito ao esquecimento, também deverá ser feita pelo método do sopesamento (utilizando-se os termos de Robert Alexy) ou pela ponderação, no caso concreto, mediante a análise dos princípios constitucionais colidentes e a escolha do princípio que se apresenta mais adequado à solução do conflito, ressalvando-se que o princípio preterido permanece no sistema. Trata-se do método de Dworkin, o "one right answer", mencionado por FACHIN, Luis Edson (2015, p. 382)

De todo modo, insta salientar que, no Brasil, a aplicação do direito ao esquecimento ainda não tem entendimento pacificado.

Caso o Supremo Tribunal Federal siga o entendimento esposado no julgamento da ADI n. 4815, quando foi privilegiado o acesso da sociedade às biografias de pessoas notórias, publicadas sem autorização prévia, o direito ao esquecimento - representando os direitos fundamentais à privacidade, imagem e honra - cederá espaço ao livre exercício da informação e promoção das liberdades comunicativas.

Por outro lado, caso o Supremo Tribunal Federal divirja do entendimento anterior e indique a prevalência do princípio da dignidade humana associado à inviabilidade pessoal, efetivando o exercício do direito ao esquecimento, isso não significará, em nossa opinião, nenhuma forma de censura, mas o reconhecimento da desproporcionalidade causado pela notícia e o desconforto gerado pela lembrança.

\footnotetext{
${ }^{4}$ Disponível em: http://www.stf.jus.br/portal/cms/verNoticiaDetalhe.asp?idConteudo=293336).

Revista de Direito Brasileira | São Paulo, SP | v. 14 | n. 6 | p. 37 - 50 | maio/ago. 2016
} 
No Brasil, os dois julgados de maior relevância que trazem, em seu fundamento, o direito ao esquecimento, pleiteiam ação indenizatória contra os órgãos de comunicação.

No REsp n. 1.334.097, o autor, inocentado da acusação de participar da chacina da Candelária, pleiteou indenização contra a Rede Globo que o indicou como coautor mesmo após sua absolvição.

Pela ocasião do julgamento no Superior Tribunal de Justiça, a $4^{a}$ Turma entendeu que o réu, condenado ou absolvido, tem o direito de ser esquecido. Utilizou-se, como parâmetro, a regra do direito ao esquecimento no âmbito penal que, após cumprimento da pena, coloca em sigilo a folha de antecedentes, excluindo os registros de condenação.

No REsp n. 1.335.153, conhecido como caso Aída Curi, os irmãos da vítima Aída, assassinada em 1958, ajuizaram ação indenizatória contra a Rede Globo pela reapresentação, anos depois, de reportagem sobre o crime.

Por ocasião desse julgamento, a mesma $4^{\mathrm{a}}$ Turma do Superior Tribunal de Justiça, no sopesamento entre a violação aos direitos de personalidade e interesse histórico, optou pela valoração do interesse público porque à época o crime se tornou histórico, entrando para o domínio público, de modo que a atividade da imprensa se mostrou inserida nos parâmetros da razoabilidade. Veja-se, in verbis:

(...) 4. Não obstante isso, assim como o direito ao esquecimento do ofensor condenado e já penalizado - deve ser ponderado pela questão da historicidade do fato narrado, assim também o direito dos ofendidos deve observar esse mesmo parâmetro. Em um crime de repercussão nacional, a vítima - por torpeza do destino - frequentemente se torna elemento indissociável do delito, circunstância que, na generalidade das vezes, inviabiliza a narrativa do crime caso se pretenda omitir a figura do ofendido. 5. Com efeito, o direito ao esquecimento que ora se reconhece para todos, ofensor e ofendidos, não alcança o caso dos autos, em que se reviveu, décadas depois do crime, acontecimento que entrou para o domínio público, de modo que se tornaria impraticável a atividade da imprensa para o desiderato de retratar o caso Aida Curi, sem Ainda Curi. 6. É evidente ser possível, caso a caso, a ponderação acerca de como o crime tornou-se histórico, podendo o julgador reconhecer que, desde sempre, o que houve foi uma exacerbada exploração midiática, e permitir novamente essa exploração significaria conformar-se com um segundo abuso só porque o primeiro já ocorrera. Porém, no caso em exame, não ficou reconhecida essa artificiosidade ou o abuso antecedente na cobertura do crime, inserindo-se, portanto, nas exceções decorrentes da ampla publicidade a que podem se sujeitar alguns delitos. (...)

Após o desprovimento da indenização, em tema de recurso especial, o caso foi reconhecido como tema de repercussão geral perante o Supremo Tribunal Federal (ARE 833.248 RJ) pela densidade constitucional, de relevância jurídica e social:

Entendo que as matérias abordadas no recurso extraordinário, além de apresentarem nítida densidade constitucional, extrapolam os interesses subjetivos das partes, uma vez que abordam tema relativo à harmonização de importantes princípios dotados de status constitucional: de um lado, a liberdade de expressão e o direito à informação; de outro, a dignidade da pessoa humana e vários de seus corolários, como a inviolabilidade da imagem, da intimidade e da vida privada. (Min. Dias Toffoli)

Em decisão datada de fevereiro de 2015, o agravo interposto em recurso extraordinário foi provido o recurso principal se encontra pendente de julgamento.

Revista de Direito Brasileira | São Paulo, SP | v. 14 | n. 6 | p. 37 - 50 | maio/ago. 2016 


\section{CONCLUSÃO}

O direito ao esquecimento deve ser reconhecido tanto pela doutrina, como pela jurisprudência brasileiras, porquanto possui fundamento no princípio da dignidade da pessoa humana (art. $1^{\mathrm{o}}$, III) e nos direitos fundamentais à privacidade, intimidade, imagem e honra, preconizados nos incisos X e XII do artigo $5^{\circ}$ da Constituição Federal. Seu fundamento também está na cláusula geral dos direitos de personalidade, previstas no Código Civil.

No entanto, com vista à própria preservação do instituto, mister se faz a ponderação jurídica acerca de seus limites materiais, justamente porque seu exercício está circunscrito a valores fundamentais. Eis o dilema: se de um lado, está a dignidade humana, valor máximo alçado na ordem constitucional de todas as nações, de outro lado, reside a liberdade de imprensa, comunicação, informação, crítica.

Eventual limitação desse direito ao esquecimento somente se dá em prol da manutenção das liberdades, principalmente a de informar e ser informado, que adquiriu ainda maior relevância após o fim do regime militar ditatorial e da revogação da Lei de Imprensa, e, principalmente, após decisão do Supremo Tribunal Federal acerca da desnecessidade de autorização prévia para publicação de biografias.

Demais disso, não se pode perder o curso da História. O passado deve ser conhecido. As relevâncias históricas não se poderão sobrepor a meros dissabores dos indivíduos.

A imprensa tem o direito e o dever de funcionar. Afinal, como pilar do estado democrático e social de direito, não deve sofrer constrição. No entanto, é seu dever diligenciar e certificar-se da correção dos fatos antes de divulgá-lo aleatoriamente.

$\mathrm{O}$ indivíduo, por sua vez, tem que tomar consciência do seu direito à autodeterminação informacional pois, conforme se der a renúncia às esferas íntimas de sua privacidade - para promover-se, por exemplo - não poderá arguir o direito ao esquecimento.

Contudo, não se olvide que o direito ao esquecimento, aqui entendido como o right to let be alone, deve ser compreendido à luz da preservação da dignidade da pessoa humana que - em uma sociedade com alta capacidade de comunicação, troca midiátia intensa e memória infinita e perpétua - adquire ainda maior relevância.

Tecidas as reflexões trazidas no presente estudo, a conclusão a que se chega é que, independentemente das novas tecnologias que surgiram e surgirão, a sociedade não deixará de demandar soluções jurídico-sociais compatíveis à preservação dos direitos fundamentais, sejam elas executadas pelo direito ao esquecimento, direito de resposta, tutela inibitórias ou indenizatórias.

O direito ao esquecimento pode deve ser reconhecido pela doutrina e jurisprudência. Seu exercício - assim como o direito de resposta - será o instrumento legítimo de defesa contra danos causados pela violação à honra, privacidade e direito de intimidade.

A esfera íntima merece proteção. A pessoa tem o direito de ser deixada em paz. Todos têm o direito de recomeçar, como assim já o quis a legislador penal.

Enfim, trazidas essas reflexões acerca da necessária ponderação, caberá à Corte Constitucional sopesar os direitos fundamentais envolvidos, no caso concreto, com a observância de suas circunstâncias especiais, a fim de que o direito ao esquecimento seja reconhecido e mantenha sua finalidade precípua de proteção e defesa às violações à privacidade, honra, imagem e dados pessoais.

\section{REFERÊNCIAS}


ALEXY, Robert. Teoria dos Direitos Fundamentais. Tradução de Virgílio Afonso da Silva. São Paulo: Malheiros Editores, 2006.

BASTOS, Celso Ribeiro. A liberdade de expressão e a comunicação social. Cadernos de Direito Constitucional de Ciência Política. RT. Julho/setembro 1997.

BIANCA, C. Massimo. Il diritto alla riservatezza. In: Valore della persona e giustizia contrattuale: scritti in onore di Adriano de Cupis. Milano: Giuffrè, 2005, p. 37- 44.

BOIZARD, Maryline. Le Droit a l'oubli. Université de Rennes 1. Mission de Recherche Droit e Justice. Rennes, 2015.

CACHAPUZ, Maria Cláudia. In Tratamento à informação sobre in(adimplemento) e banco de cadastro positivo: registro, esquecimento e ilicitude. Porto Alegre: Sergio Antonio Fabris, 2014.

CACHAPUZ, Maria Cláudia. Intimidade e vida privada no novo Código Civil brasileiro: uma leitura ordenada no discurso jurídico. Porto Alegre: Sergio Antonio Fabris, 2006.

CHEHAB, Gustavo. O direito na sociedade da informação. Revista dos Tribunais, v. 104, n. 952, 2015.

CORDEIRO, Antonio Menezes. Tratado de direito civil português. 2. Ed. Coimbra: Almedina, v. 1, tomo 3, pessoas, 2007

FACHIN, Luis Edson. A liberdade e a intimidade: uma breve análise das biografias não autorizadas. In: SIMÃO, José Fernando; BELTRÃO, Silvio Romero (Coord.). Direito civil: estudos em homenagem a José de Oliveira Ascenção: teoria geral do direito, bioética, direito intelectual e sociedade da informação. Volume 1, São Paulo: Atlas, 2015.

FACHIN, Zulmar Antonio. A proteção jurídica da imagem. São Paulo: Celso Bastos Editor instituto brasileiro de Direito Constitucional, 1999.

FERNANDES, Milton. Proteção civil da intimidade. São Paulo: Ed. Saraiva, 1977.

HUNGRIA, Nelson. A nova Lei da Imprensa, Comentários ao Código Penal. Forense: 1958

IZQUIERDO, Iván. A Arte de Esquecer: cérebro, memória e esquecimento. 2. ed. Vieira \& Lent. 2010 apud MOUTINHO, Bruno Martins. Reconhecimento do Direito ao Esquecimento como um Direito Fundamental. In: $O$ Reconhecimento dos Novos Direitos da Personalidade. Maringá: Editora Vivens, 2015, p. $304-327$.

JUNIOR, Otávio Luiz Rodrigues. 2013. Disponível em: http://www.conjur.com.br/2013-dez25/direito-comparado-nao-tendencias-protecao-direito-esquecimento\#_ftn10

Karl Larenz/Claus-Wilhelm Canaris, Lehrbuch des Sclwldrechts, II- Besonderer Tei/, 2. Halbband, 13' ed., Munchen, 1994, § 80, esp. p. 498 e ss. Apud PINTO, Paulo Mota. Notas sobre o direito ao livre desenvolvimento da personalidade e os direitos da personalidade no direito português. In: A constituição concretizada: construindo pontes com o público e o privado. Porto Alegre: Livraria do Advogado, 2000. 
Celso

de.

Disponível

em:

http://www.stf.jus.br/portal/cms/vernoticiadetalhe.asp?idconteudo=107402

MELLO, M.A., In Liberdade de Expressão, Dignidade Humana e Estado Democrático de Direito, apud Tratado Luso-Brasileiro da Dignidade Humana, $2^{a}$ ed., Miranda, Jorge; Marques da Silva, M.A., Quartier Latin, 2009.

MIRANDA, Darcy Arruda. Comentários à Lei de Imprensa. São Paulo: RT, 1994.

MOUTINHO, Bruno Martins. Reconhecimento do Direito ao Esquecimento como um Direito Fundamental. In: O Reconhecimento dos Novos Direitos da Personalidade. Maringá: Editora Vivens, 2015, p. $304-327$.

NIETZSCHE, F. Généalogie de la morale. Flommarion, 1996 apud BOIZARD, Maryline. Le Droit a l'oubli. Université de Rennes 1. Mission de Recherche Droit e Justice. Rennes, 2015.

NOVOLENE, Pietro. Reati di Stampa, apud SERPA, José. Direito à imagem, à vida e à privacidade. Belém: CEJUP, 1994.

PINTO, Paulo Mota. Notas sobre o direito ao livre desenvolvimento da personalidade e os direitos da personalidade no direito português. In: A constituição concretizada: construindo pontes com o público e o privado. Porto Alegre: Livraria do Advogado, 2000.

RODOTÁ, Stefano. A vida na sociedade da vigilância: a privacidade hoje. Tradução de Danilo Doneda e Luciana Cabral Doneda. Rio de Janeiro: Renovar, 2008, p. 23-109.

RULLI JUNIOR, Antonio; RULLI NETO, Antonio. Direito ao esquecimento e ao superinformacionismo: apontamentos no direito brasileiro dentro do contexto de sociedade da informação. Revista do Instituto do Direito Brasileiro. Lisboa: Faculdade de Direito da Universidade de Lisboa. V. 1. P. 419-434, 2012.

SCHREIBER, Anderson. Direitos da Personalidade. 2 ed. São Paulo: Atlas, 2013

SERPA, José. Direito à imagem, à vida e à privacidade. Belém: CEJUP, 1994.

ZULIANI, Enio. Comentários à Lei de Imprensa. Lei 5.250/1967 - Artigo por artigo. São Paulo: Editora Revista dos Tribunais: 2007. 